\title{
EVOLUTION OF MACHINE RELIABILITY AND LIFE AND ECONOMICS OF OPERATIONAL USE
}

\author{
Stanisław Młynarski \\ Cracow University of Technology, Institute of Rail Vehicles, Poland \\ Corresponding author: \\ Stanistaw Mtynarski \\ Cracow University of Technology \\ Institute of Rail Vehicles \\ Jana Pawla II 37, 31-864 Kraków, Poland \\ phone: (+48) 12 628-33-22, 12 374-33-10 \\ e-mail:mlynarski@m8.mech.pk.edu.pl
}

Received: 27 April 2016

Accepted: 9 November 2016

\begin{abstract}
The article presents new assumptions for reliability and life of machines, resulting from the development of technology. The innovative approach to reliability and life design as well as warranty duration planning is presented on an example of vehicle reliability characteristics. A new algorithm is proposed for the replacement of repairable objects costs by the price of life and reliability of new unrepairable ones. For the planning of the life of innovative machines, an effective method of technical progress rate determination is proposed. In conclusion, necessary modifications of machine and vehicle use systems, resulting from technology evolution and technical progress, are indicated. Finally, recommendations and directions of indispensable research in engineering and management of technical means of production are formulated.
\end{abstract}

KEYWORDS

reliability, service life, innovation, optimisation, economics, operational use, technological progress.

\section{Introduction}

One of the essential elements of economic growth is the means of production. They are the chief stimulator of engineering/technical progress. The evolution of machines is an exponent of industrial development. The evolution of machines and methods of their manufacture is accompanied by the evolution of the surroundings and the principles of their use, that is operational systems. As concerns the efficient use of machines, apart from the safety of their operation and principles of their use the operational economics is of crucial importance. At the initial stage, the changes in the industrial economy are clearly aimed at economic factors. A thorough analysis of these changes reveals a number of engineering factors. Such factors are strictly connected with the evolution of engineering and technology applied. These links were noticed quite early. One of the major publications in the past years (neoclassicism) is the article by R. Solow (1957) [1] in which he argued that the influence of engineering and technology development is directly immeasurable. However, an indirect measurement can be done by means of various indirect symptoms. This effect is most evident in the changes that occur in technical means [2-5]. The machine design of today approach the extreme values of its achievements such as quality, efficiency and economics of machine operation. The properties of machine reliability and life are often of key importance for the improvement of parameters and potential of their application.

The aim of the paper is to present the research on innovative modifications in the use of machines and vehicles, connected with the current development of engineering and technology. The objective of the performed research is achieved by:

- identification of innovative features of the exploitation system affected by the change of the properties of new machines,

- characteristics of the changes of design and reliability indices as well as the effect of these fac- 
tors on warranty duration for the machines, determined by technological progress.

To achieve the research objectives mentioned an analysis of the actual changes in real-life exploitation systems for the time horizon of thirty-year observation/monitoring was carried out. Apart from the changes of the technological and economic factors, the research covers the changes of functional and ecological safety in the analysed period. The results of the research and analyses performed are discussed in subsequent sections of the paper.

\section{Innovations in machine reliability and life}

The combination of several trends in the application of machines in economy demands changes in their design in the aspect of reliability and life as well as the safety of their operation and surroundings.

The application of precise and fast tools in testing reliability and life is ever more indispensable in, first of all, design and manufacture of new constructions of engineering objects [6-8]. The development of engineering and technology sets more and more demanding requirements of both technical and economic parameters. The new standards and regulations put restrictions on the possibility of using machines and equipment which are efficient enough in the tasks they were designed for originally but are not able to meet the technical, economic and ecological requirements valid today. The trend of sustainable development occurring in the global economy prefers ecological conditions that directly stimulate the technical and economic factors. They are a major determinant of machine construction in many areas of the economy $[5,9,10]$. Consequently, it is necessary to design and manufacture new machines and devices of very high reliability and limited, planned by the designers, life. This tendency has been observed and applied recently by manufacturers of various technical objects [11]. The observations of development tendencies of machine design and operation indicate the parameters and features determined by the advancement in engineering and technology, which has been shown in Fig. 1 .

The ability to assess the period in which the designed object will perform properly its pre-assigned tasks incompatibility with the standards and regulations in force now or the changing tendencies is only the beginning for the design of an appropriate life of the object. Newly designed machines and devices should have an optimal life. This means that their life should not be too short because then the object is not efficient in its operation. It should not be too long, either, because it will not be efficient due to higher manufacture costs and the necessity of withdrawing it from the operation because of its not meeting the requirements of changing needs, regulations and standards.

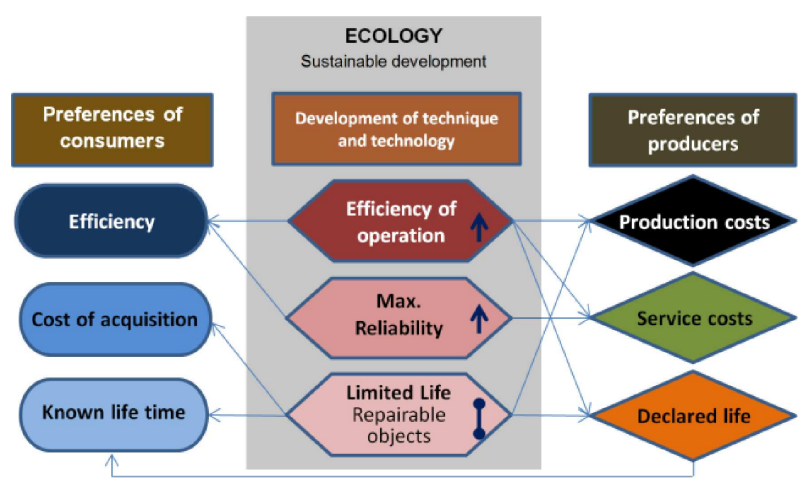

Fig. 1. Trends in machine and equipment development in conditions of engineering progress.

Manufacturers of machines and vehicles nowadays frequently use the concept of reliability and life as marketing values [12]. What is important for future users is the warranty period provided by machine and vehicle producers. Algorithms, i.e. certain mathematical and logical methods assisted by specialist computer programs enable to precisely enough define the machine or vehicle operation period covered by the warranty. The warranty period is strictly connected with the value of the reliability indices of a given type or kind of machines which constitute a certain population of technical objects. However, in actual reality, it is determined by the expenditure born by the manufacturer to remove unserviceability of the objects vulnerable to failure during the warranty period. In $[6,8,11]$ the authors propose a way of calculating the warranty period depending on the object class (unrepairable and repairable) with a suggestion of bilateral incurring risk and cost during the warranty period by both parties, i.e. the manufacturer and buyer. Such interpretation in a general format for unrepairable objects can be presented as a total loss by the dependence:

$$
\begin{gathered}
k=k_{n} n p \alpha+k_{p} n(1-p) \beta, \\
\alpha=1-F_{N}(t), \\
\beta=F_{Z}\left(t_{g}\right) .
\end{gathered}
$$

For the condition of total loss minimisation $\alpha$ and $\beta$ should be substituted in formula (1) and derivative after time $\mathrm{t}$ equated zero.

$$
\frac{d k}{d t}=0
$$


The warranty period is established in the units of time and only in few cases this constraint is assisted by other units adequate to the character of the object's operation. Practically, however, for all machines and vehicles the measure of the warranty period is the calendar period of service life $t_{g}$ :

$$
t_{g}^{k}=\frac{t_{g}}{\lambda_{u}},
$$

where $p$ - probability of unserviceability, $k_{n}$ - unitary loss to purchasers, $k_{p}$ - unitary loss to producers, $n$ - size of lot or object population, $F_{Z}(\mathrm{t})$ - objects with no latent defects, $F_{N}(\mathrm{t})$ - objects with latent defects, $t_{g}$ - the warranty period, $\lambda_{u}$ - failure rate, $\alpha$ - tolerable availability probability, $\beta$ - tolerable failure probability.

In practice, the warranty time is determined by the value of future costs incurred by the manufacturer to remove unserviceability resulting from the probability of survival function $R(t)$ distribution. These costs depend on the unserviceability incidence in the warranty period and unitary costs of such unserviceability. Consequently, the time period established as the warranty period is determined by the value and curve of the survival function.

Starting from the basic assumptions related to the calculation of the survival function it is assumed that:

$$
R(t)=P(T>t),
$$

where $T$ - machine service life, $t$ - machine operation time to failure, $R(\mathrm{t})$ - survival function at moment $t$ of machine service life for which it is assumed that at the start of service $t=0$. It is also assumed that over the time period analysed for the needs of warranty machines are considered as unrepairable objects. For such an approach the operation time to failure equals the machine service life. In practice, in the analysis of machine reliability and life assessment the function of machine failure probability is used:

$$
Q(t)=P(T<t)=F(t) .
$$

Function $Q(t)$ is the distribution function of random variable $t$ which is the machine service life time.

In empirical investigations of a set of machines, empirical indices of reliability are deployed. The value of reliability empirical function can be calculated from formula:

$$
R_{E}(t)=1-Q(t)=1-\frac{m(t)}{N}=\frac{n(t)}{N},
$$

where $R_{E}(t)$ - empirical value of reliability function at time $t, Q(t)$ - value of failure probability density function at time $t, N$ - power of the set of machines available for service at time $t=0, n(t)$ - amount of serviceable machines at time $t, m(t)$ - amount of unserviceable machines at time $t$.

The average time of machine's correct operation to failure can be calculated from the dependence:

$$
\bar{T}_{E}=\frac{\sum_{j=1}^{N} t_{j}}{N} \approx \frac{\sum_{i=1}^{k} \Delta m_{i} \bar{t}_{i}}{N} .
$$

The characteristics of reliability indices are based on the distribution and parameters of machine's correct operation. On the basis of the analysis of the reliability indices characteristics, the boundary values of these indices are determined. The level of the boundary values, however, depends on a number of factors including the type of machine, character of operation and external conditions which are defined by design assumptions related to operation safety or the economics of service life. The warranty period results from the functional dependence of the reliability index value and can be derived from the characteristics curve. What may be useful in determining the warranty period is the characteristics of the survival function and distribution function as a function of fallibility. Determination of the boundary values defines the operation time of the machine or vehicle. The boundary value is directly connected with the a number of failures and the resulting repair costs as well as other costs related to machine unserviceability. An example of graphic presentation of an alternative warranty period has been shown in curves plotted using Weibull++ program (Figs. 2 and 3).

The analysis of the curves can be a basis for concluding about the design and quality of the machine manufacture. Characteristic $R_{1}(t)$ presents the course of the value change distributed gradually over time. Such a character of the course can constitute problems related to the failure risk and availability of the machine or vehicle. On this ground, conclusions can be drawn as to the low quality of the manufacture of machines structural elements. Such a course is typical of older machines of a complex structure and a large number of structural elements. Characteristic $R_{2}(t)$ illustrates the course of the character desirable in currently manufactures machines. The application of methods of machine service life and reliability control, high-quality technologies and materials contribute to the construction of machines of threshold values of reliability characteristics, of high reliability over the required time interval, followed by a sudden loss of serviceability. The characteristic of such a course indicates the maturity of the design and good quality of manufacture. 

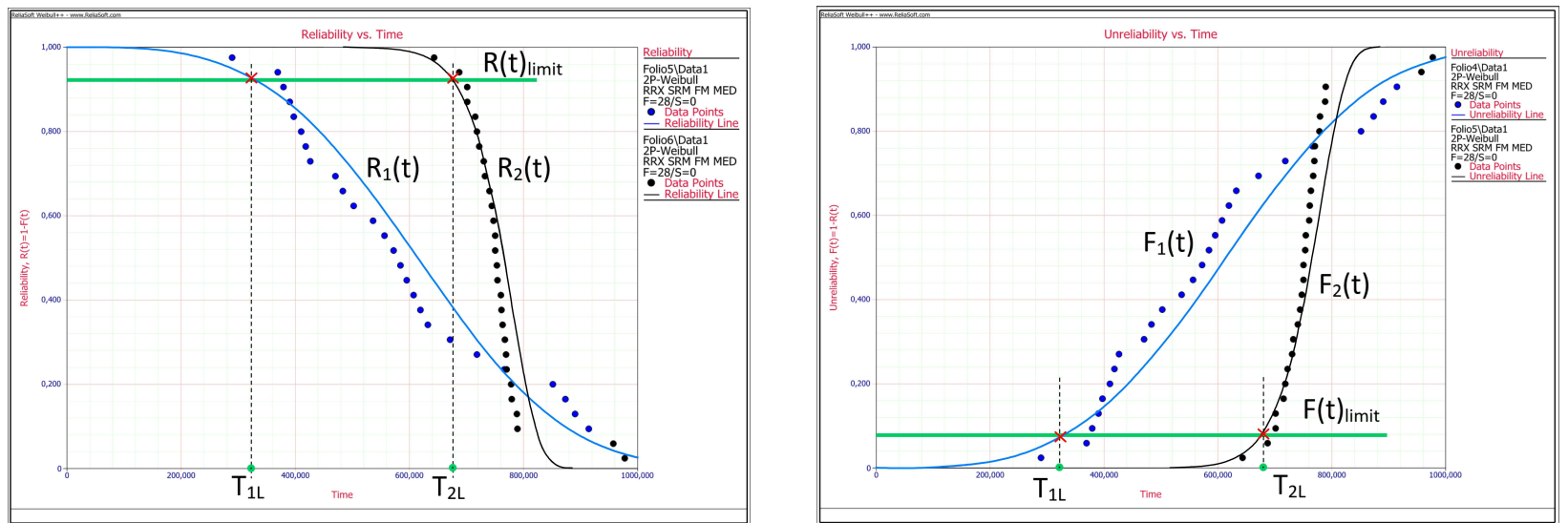

Fig. 2. Determination of warranty period for two different courses of reliability function $R(t)$ and distribution function $F(t)\left(T_{1 L}<T_{2 L}\right)$ for $R_{\text {limit }}$ and $F_{\text {limit }}=$ constant.
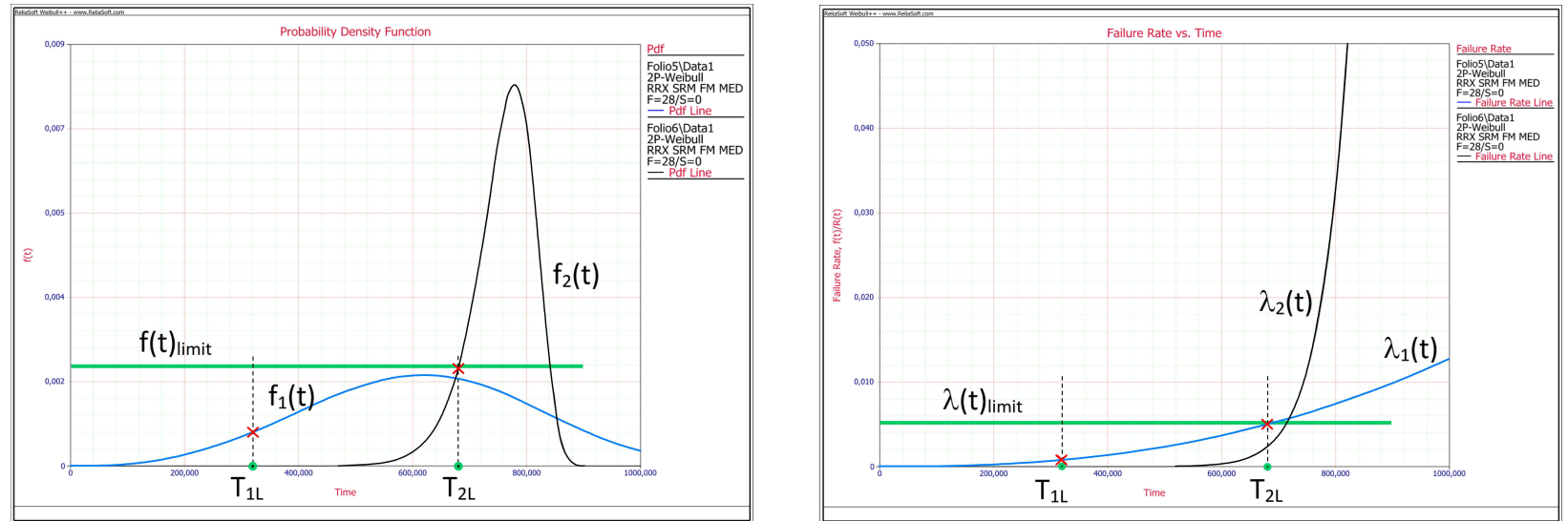

Fig. 3. Determination of warranty period for two different courses of failure density function $f(t)$ and rate $\lambda(t)$ $\left(T_{1 L}<T_{2 L}\right)$ for $f_{\text {limit }}$ and $\lambda_{\text {limit }}$.

What is of extreme usefulness to machine manufacturers is the characteristics of failure density and rate.

The knowledge of the character of the course of failure density function gives insight into the scale of the problem of failures and enables determination of the warranty period before reaching a sudden increase or extremum of the value of the function.

The failure rate function, on the other hand, is particularly important in the assessment of the functional safety of machines and vehicles. The determination of the manufacturer's warranty period by machine's functional safety can be established on the basis of defining the boundary values of this function. The characteristics of the density and failure rate functions make it possible to plan prophylactic servicing before the machine's failures cumulate. On the basis of the analysis of the characteristics the machine's service life covered by the warranty can be defined. This determination includes a certain allow- able tolerance of a number of failures before failure intensity cumulation occurs.

Inference based on reliability characteristics is a significant source of information on the design and operation of machines and vehicles [13].

\section{Optimal period of machine and vehicle operational use period in the conditions of technological progress}

The considerations so far have been done assuming machine's reparability and its longest possible service life. Such an assumption indicated that an essential problem in machines operational use is the possibility of their regeneration. Then one of the major operation indices is the mean time to failure $M T T F$, which can be identified with the mean time between failures. It should be noticed that what is meant by failure in case of repairable products is the depletion of work capacity, followed by an attempt at 
regeneration. Consequently, MTTF is the mean time to regeneration and has fundamental importance for the realisation of a manufacturing task and considerable effect on operational costs

$$
M T B F=M T T F+M T T R=E \tau+E \tau r,
$$

where $M T T F$ - mean time failure (depletion of work capacity), MTTR - mean time to regeneration, $E \tau$ - expected service life, $E \tau r$ - expected repair time.

Assuming that Weibull distribution is the most frequently used model of probability distribution of machines real failures, to define the time to failure the following dependence can be used

$$
\begin{gathered}
T_{s r}=\int_{0}^{t} R(T) d t, \\
R(T)=e^{-\frac{T^{\alpha}}{\beta}}, \\
M T T F=T_{s r}=\int_{0}^{\infty} e^{-\frac{T^{\alpha}}{\beta}} d t, \\
M T T R=T_{R}+T_{O R}+T_{W}+T_{B M},
\end{gathered}
$$

where $\alpha$ - parameter distribution curve form, $\beta$ parameter describing distribution scale, Tsr - mean time of serviceability, $T_{R}$ - repair works time, $T_{O R}$ - repair organisation time, $T_{W}$ - failure verification time, $R_{B M}$ - spare parts delivery time.

The mean time to failure, which is the operation time, directly affects the profit resulting from machine's work, which can be calculated by establishing the profit per time unit. The real total profit as a sum of profit $\mathrm{Z}$ can be calculated from formula:

$$
Z=\int_{0}^{T} D_{t}-E|T| e^{r t} d t+S|T| e^{r t}-C_{0},
$$

where $Z$ - dependent variable as a sum of profits, $|T|$ - independent variable as the magnitude of operational use period, $D_{t}$ - profit per time unit, $C_{0}-$ initial cost, $E$-operation cost, $S$-values of residue, $r t$ - time variable interest rate of value loss.

The analysis of machine service related costs indicates certain features of the effect of technological progress on the cost of investment means born during the product service $[14,25]$.

$E(T)$ - service costs decrease with the technological, $C_{0}(T)$ - initial costs (of purchasing a machine) increase with the technological progress.

In searching for the time of machine's work over which the maximum profit is reached a derivative is differentiated on the basis of (10) in reference to machine service time, as independence (16)

$$
\frac{d Z}{d t}=D_{T}-E|T| e^{r t}-r S|T| e^{r t}+S^{\prime}|T| e^{r t},
$$

where $D_{T}$ - revenue in the machine's total work time, $E|T|$ - operational costs over the same time period, $r S|T|$ - loss of value resulting from the operation of the machine, $S^{\prime}|T|$ - additional depreciation to $S(T)+\Delta S(T)$.

The condition for determining machine service life necessary to obtain the maximum profit is to check the work time after which the profit derivative takes the value of zero

$$
\begin{gathered}
\frac{d Z}{d t}=0 \\
D_{T}-E(T)-r S(T)+S^{\prime}(T)=0 \\
D_{T}=E(T)+r S(T)-S^{\prime}(T) .
\end{gathered}
$$

This condition is met when the total income equals the total cost.

The introduction of new models of machines and vehicles in industry significantly affects the value of the optimal period of their service life. The effect of technological progress in the form of new highly advanced technologies is manifested by the implementation of machines of a new generation that can meet the current manufacturing requirements. The applied technologies and the technically complex structures obtained frequently pose a serious problem of their servicing in the case of damage to the component parts. This problem increases with the technological complexity of the machine design $[15,16]$. It happens more and more often that the technical solutions used for the production of machine components or their systems cannot be reproduced outside the production plant due to their high technological advancement. Such cases determine manufacturers to produce products of the modular structure. This approach enables the servicing and repair of machines and vehicles in a fast and simple way without requiring the full knowledge of the internal structure and advanced technology of machine structure. It can be presumed that such a solution is merely a temporary method while the target to be reached is the design followed by construction of unrepairable machines and vehicles of very high reliability, intended service life. Consequently, it is necessary to maximise reliability, optimise service life and costs of the operational use of machines and vehicles depending on the adopted operational assumptions. In considering the feasibility of optimisation of machine properties the key feature is service life [17-19]. It determines the economic parameters and is directly connected with the amortisation of production means. In deliberating on the factors determining the optimisation of service life what is of absolute importance is the index of technological progress. Up till now, 
it was desirable for machines to have longest possible service life including their successive reproduction. Due to fast technological progress and increasingly greater requirements machines, after a short operational use, becomes inefficient. This essentially changes the approach followed so far and makes it indispensable to design machines of limited known service life and high reliability. The determination of an intended service life of a machine over a certain economically defined range of machine service is inversely proportional to the technological progress, which means that the faster the technological progress the shorter machines' service life due to the rationality of technological application.

Consequently, It is important to define a machine's service life already at the stage of its design. Making assumptions on the basis of machine operational use, properties and type of design as well as the development of technology and techniques it is possible to calculate machine service life economically sound and determined by technological progress. The calculation can be done from the dependence of equating the classical approach to the operational use of repairable products and the new approach for unrepairable products. Dependence [15] enables a simplified calculation of the minimum service life of a new non-reproducible machine, which can replace the service life of a machine subjected to cyclic reproductions

$$
\begin{gathered}
\sum_{i=1}^{n}\left[\left(D_{A}-O_{A}-E_{A}\right) * T_{P}\right]-K_{A Z}+W_{P A} \\
=\left(D_{B}-E_{B}\right) * T_{B}-K_{B Z}+W_{P B}, \\
\sum_{i=1}^{n}\left[\left(D_{A}-O_{A}-E_{A}\right) * T_{P}\right]-K_{A Z}+W_{P A} \\
\quad+K_{B Z}-W_{P B}=\left(D_{B}-E_{B}\right) * T_{B}, \\
T_{B}=\frac{\sum_{i=1}^{n}\left[\left(D_{A}-O_{A}-E_{A}\right) * T_{P}\right]-a^{*}}{D_{B}-E_{B}},
\end{gathered}
$$

where

$$
a^{*}=K_{A Z}+W_{P A}+K_{B Z}-W_{P B},
$$

$D_{A}$ - unitary income during service time to each reproduction of machine, $T_{p}$ - number of service time units expressing partial service life of machine, $T_{B}$ - number of service time units expressing the total service life of machine, $n$ - number of predicted processes of machine reproduction, $O$ - costs of product reproduction per service time unit, $E_{A B^{-}}$costs of immediate operational use (operational materials and fixed costs) per product service time unit, $K_{Z}-$ cost of purchase of new product, $W_{P}$ - residue value (disposal of product), $A$ - reproducible product, $B$ non-reproducible product.

Determining a rational operational period of operational use and defining the economically justified service life of a machine a certain investigation can be carried out adopting some simplified assumptions. It is assumed that technological progress results in a change of machine purchase prices, amortisation, disposal value, the number and quality of the products produced by new machines. However, in view of the high reliability assumed, the annual machine maintenance costs in an ideal case appear only as planned fixed costs of materials and operational elements $\left(E_{B}\right)$. As the technological progress in machine design proceeds, the annual operational costs first decrease and next stabilise. The operational costs of new machines do not include reproduction costs because the reproduction of these highly advanced technologically products is impossible and in practice means the production of a new machine. It is evident that machines and vehicles currently designed require each year lower costs than the products installed twenty years earlier, increasing the production capacity or mileage for vehicles. The image of the process can, however, be distorted by frequent overestimation of indirect costs that are charged during machine servicing. Due to technological progress, the economic and functional values of machines and vehicles decrease with time and lead to the reduction of capital in the form of material assets of businesses equipped with old equipment. Another very important factor is the reduction of yearly income due to the lack of possibility to meet the current quantitative and qualitative demands of machines manufactured a few years earlier $[6,20,21]$. Therefore the technological progress must lead to the reduction of service life of technical means and the introduction of new machines and vehicles more effective and safer in operation The criterion of restricting the service life depends on the type of tasks the product performs, specificity of its work and construction. In the considerations on operational period, and consequently the predicted service life, of technical objects it is necessary to identify the leading features and foresee the dynamics of technological progress in the given area. Therefore, when some groups of objects are set apart from a machine population it is possible to assign the features that will directly determine the service life due to changes resulting from technological progress. 


\section{Assessment of technological progress indices}

With time the effects of machine work increase. This is a practical measure of technological progress. Since it is necessary to evaluate and assess the process of technological progress, it is possible to define the indices of the service life of machines and vehicles that carry the features of changes occurring in technology $[3,20,21]$. Such an evaluation can be done including various criteria of machines' functioning. Two essential criteria are technology and economic. The economic factors are an important element in stimulating and developing technological creativity [9, 14, 22]. However, in the absolute approach to the problem at this stage of considerations, the criterion of technology is the leading issue. Time intervals of the service life of vehicles between successive technical servicing periods can be one of the good indices reflecting the evolution proceeding in an applied technology. Vehicles belong to most commonly used machines and due to their construction producing them requires solutions from the majority of fields of technology. At the same time, vehicles' operation takes place in a great variety of conditions. This variety makes vehicle objects of considerable sensitivity to changes in technology and techniques. Consequently, they may be used as a good measure of technological evolution. Analysing the feasibility of assessment of technological progress a simplified, but of practical application way has been proposed. An analysis of the historical data from a twenty-fiveyear operational use of vehicles has been performed. Time intervals of vehicle mileage between successive servicing operations or renewal, determined by manufacturers, have been used. The evolution of vehicle servicing process in the form of mileage intervals between servicing operations has been illustrated in Fig. 4. The analysis covered successive years of manufacture over the entire analysed period.

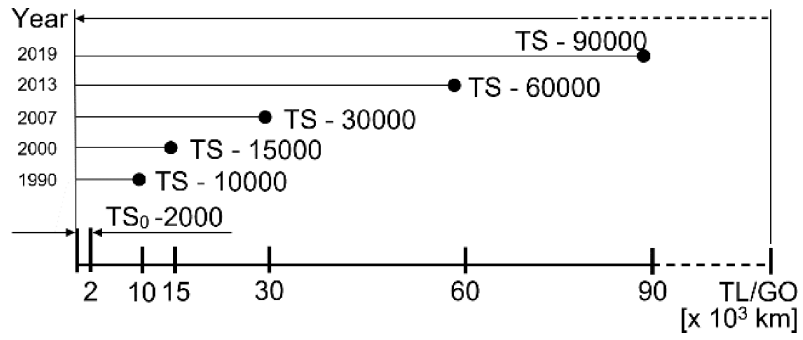

Fig. 4. Dynamics of servicing-repair cycle of buses used following recommendations of the vehicles manufacturers in the years 1990-2019: TS - zero survey, TS - technical service, GO - general overhaul, TL - sale/vehiclebreaking.
It was assumed that since time $t=1$ which was chosen to be 1990, each year new improved vehicles were delivered for operational use. The measurement of technological progress was performed by identifying this parameter with the time interval between technical services assigned by the manufacturers. Higher mileage between services means more technologically advanced product yielding greater profits with no extra costs and downtime. Historically, the year 1990 assigned at the beginning of the analysis has a key importance for our considerations. It was then that the process of introducing electronics and computer assisted solutions to the design of vehicles and other machines. And it was this factor that constituted the new potential in further technological progress. This period of time is perfect for doing research and taking decisions on the future development of technology. On the basis of the analysis correlation coefficients of the measurement of technological progress dynamics were determined. Next, an attempt was made to calculate the vehicles' planned service life using the technological progress dynamics as a criterion. The calculations were based on the statement that owing to technological progress the vehicles that fail to meet the requirements of new regulations and economic standards will be eliminated from operation in a natural way. The results of the calculations have been shown in a table (Table 1) and characteristics plots (Fig. 5).

Table 1

Data relevant for measuring the dynamics of technical progress.

\begin{tabular}{c|c|c|c|c}
\hline $\begin{array}{c}\text { Year } \\
\text { of } \\
\begin{array}{c}\text { introducing } \\
\text { service } \\
\text { standard } \\
\text { [years] }\end{array}\end{array}$ & $\begin{array}{c}\text { Service } \\
\text { interval } \\
{\left[\times 10^{3} \mathrm{~km}\right]}\end{array}$ & $\begin{array}{c}\text { Interval } \\
\text { of } \\
\text { introducing } \\
\text { standard } \\
\text { [years] }\end{array}$ & $\begin{array}{c}\text { Correlation } \\
\text { coefficient } \\
\text { TP } \\
\text { WKTP }\end{array}$ & $\begin{array}{c}\text { Planned } \\
\text { service } \\
\text { life TP } \\
\text { [years] }\end{array}$ \\
\hline 1990 & 10 & 10 & 1.00 & 30.00 \\
\hline 2000 & 15 & 10 & 1.50 & 22.00 \\
\hline 2007 & 30 & 7 & 4.29 & 9.00 \\
\hline 2013 & 60 & 6 & 10.00 & 5.00 \\
\hline 2019 & 90 & 6 & 15.00 & 4.00 \\
\hline
\end{tabular}

The characteristics of the correlation coefficient of planned service life actually illustrate the dynamics of the technological progress. The characteristics expose a clear value increase from the year 2000, while from the year 2007 a stabilised aggressive increase reaching the year 2019 as the prognosis period is evident.

The curve of the characteristic is by no means surprising and reflects the natural conditions of development. On the other hand, the process of the correlation coefficient of technological progress (WKPT) affecting service life and reliability of vehicles and 
machines looks interesting. Simultaneously, an improvement of many parameters such as functional safety, the economics of operational use as well as ergonomics and comfort of use of machines and vehicles is observed. These changes are followed by regulations and standards as well as natural factors that regulate the possibility of using technological means in the economy. What is important in the process is the economics of operational use which stimulates in a natural way the use of machines and vehicles. The presented facts prove that the period of machines' operating in the economy depends on the properties and parameters determined by the technological progress.

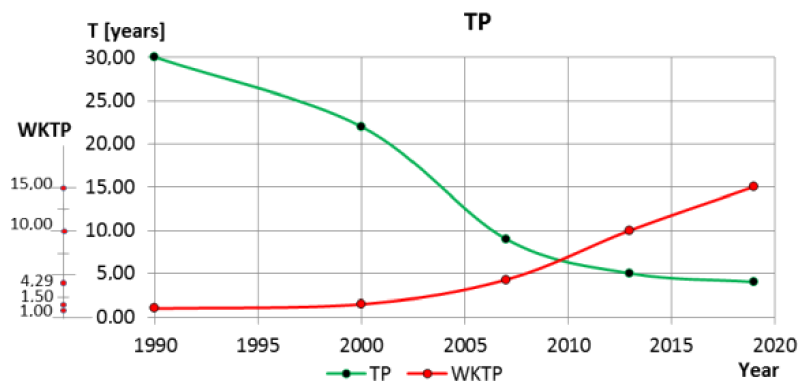

Fig. 5. Characteristics of dynamics of technological progress measurement technical parameters: TP planned service life, WKTP - correlation coefficient of planned service life in the conditions of technological progress.

From the considerations above it follows that the higher the technological progress dynamics the lower the planned service life.

$$
T_{\left(T_{0}+1\right)}=T_{0} / W \operatorname{KTP}_{\left(T_{0}-1\right)} .
$$

Analysing the second characteristic shown in the diagram, which illustrates the changes of planned service life of vehicles in the years 1990-2019, characteristic intervals of the curve trace can be observed. The first interval covers the years 1990 to 2000 during which a moderate drop in planned service life is observed. In the next interval, the years 2000 to 2007, the characteristic suddenly drops and the products' service life is lower. This period is followed by stagnation resulting from technological saturation and approaches the ultimate service life. The results of the validation of vehicles' predicted life are verified by:

- assessment of the passenger and cargo transport performance,

- changes in environmental rules and standards together with their effect on vehicles' operational life duration,

- regulations concerning depreciation of fixed assets, binding in the management of companies' fixed assets.
Another problem the declaration of the high reliability of machines and vehicles. High reliability of machines directly affects such obvious effects as safety and economics of operational use. Great reliability, however, is of essential importance for the manufacturers of machines and vehicles. This significance increases with the technological advancement of a machine or vehicle. In the case of failure of technologically advanced machines, the repair requires specialist facilities and knowledge of the structure of the damaged products. High reliability and known service life are a basis for the manufacture of unrepairable products, but much lower production costs resulting, for example, from the structures not requiring dismantling.

\section{Final conclusions}

The development of technology and techniques involves improved design possibilities and improvement of machines operation parameters. The dynamics of the process imposes limitations on the service life of the machines used. This, in turn, decreases the efficiency of their operation and failure to meet new standards and norms [26].

The aim of the presented results of the analysis of the dynamics of vehicles service life determined by the technological progress is to identify the problem and indicate the trend of the occurring changes.

There are three basic areas in which research should be conducted to find solutions to the problem discussed.

The first area involves the assurance of the required level and the reliability characteristics pattern indispensable for the safety, economy and proper operation of the machine.

The second area is related to the determination of machines service life resulting from the trend and dynamics of the technological development.

The third area covers the methods of manufacture and transport means management in the aspect of the operational use economics determined by the technological development dynamics [23, 24].

Successful solution of the problems of machines' reliability and service life in the aspect of technological progress is reduced to:

- development of formalised models of service life and reliability assessment in the conditions of fast technological advancement,

- determination of optimal technologies and design solution for vehicles,

- forecasting service life and reliability of machines during their operational use to design new machines and vehicles, 
- development of machine service life and reliability standards taking into account technology and techniques advancement,

- development of operational use systems and replacement of technical means taking into account the evolution of machines service life and reliability standards.

Currently research on the operational use of manufacture technical means is focused:

- increasing the reliability and safety of machines and vehicles operation,

- standardisation of structural elements services life,

- reduction of manufacture costs.

To carry out these tasks the following targets are aimed at:

- implementation of programmes and methods of testing operational life and reliability,

- determination of boundary states to detect "weak cells" of the structure,

- forecasting controlled service life in design and manufacture of machines and vehicles,

- implementation of methods and new criteria of technical and economical assessment manufacture technical means service life and reliability.

The summing up the conclusion of the presented analysis refers to the evolution of the system of use and servicing of new machines. The constituents of operational use such as limited service life, unrepairable structures and the resulting problem of recovering the machine's availability after failure demand a change in the approach to the use of technical means. Users employing machines in their economic activity more and more frequently purchase only the "function" of a machine or the so-called "mobility" in the case of vehicles. The problems of reliability and service life are left to machine manufacturers to cope with. Such an approach causes significant modifications of the servicing system and strategy of management of machines and vehicles resources. The process is in progress and all industries are affected.

Therefore it is essential to perform research on the process taking place and to develop new principles of fixed assets control, which will cover the changes in the issues discussed in the paper.

\section{References}

[1] Solow R., Technical Change and the Aggregate Production Function, Review of Economics and Statistics, no 2, 1957.

[2] Feldman M., The New Economics Of Innovation, Spillovers And Agglomeration: A Review Of Empirical Studies, Economics of Innovation and New Technology, 8, 1-2, 5-25, 1999.
[3] Gawlik J., Motyka S., Forecasting of efficiency of innovative machining products implementation [in Polish: Prognozowanie skuteczności wprowadzania innowacyjnych wyrobów przemystu maszynowego], Inżynieria Maszyn, Wydawnictwo Wrocławskiej Rady FSNT NOT, 11, 4, 5-16, 2006.

[4] Godin B., The Linear Model of Innovation, The Historical Construction of an Analytical Framework, Science Technology Human Values, 31, 6, 639-667, November 2006.

[5] Romer P.M., Endogenous Technological Change, Journal of Political Economy, 98, 5, 1990; Part 2: The Problem of Development: A Conference of the Institute for the Study of Free Enterprise Systems, pp. 71-102.

[6] Migdalski J., Editor, Reliability engineering - guide [in Polish: Redakcja, Inżynieria niezawodności - poradnik], ATR-ZETOM, Warszawa 1992.

[7] Mosse' P., Optimal Investment Decision, Prentice Halls, pp. 58, 1962.

[8] Manzini, R., Regattieri, A., Pham H., Ferrari E., Maintenance for Industrial Systems, London, Springer-Verlag Gmbh, 16, 397-408, 449-454, 2010.

[9] Dostatni E., Diakun J., Agent-based supporting system for environmental assessment of products, Management and Production Engineering Review, 1, 1, $7-16,2010$.

[10] Pająk E., Kowalski M., Paszkiewicz R., Wichniarek R., Zawadzki P., Dudzik A., Technical and economic coefficients of multi-directional production of parts by incremental methods, Management and Production Engineering Review, 1, 3, 56-62, 2010.

[11] Murthy D.N.P., Product warranty and reliability, 143, 1, 133-146, 2006.

[12] Swan K.S., Allred B.B., A product and process model of the technology-sourcing decision, Journal of Product Innovation Management, 20, 6, 2003.

[13] Myerson R., Probability models for economic decisions, Duxbury Applied Series, 3, 824, 2005.

[14] Lucas R.E., On the Mechanics of Economic Development, Journal of Monetary Economics, 22, 342, 1988.

[15] Grossman G.M., Helpman E., Innovation and Growth in the Global Economy, MIT Press, Cambridge, 1991.

[16] Tidd J., Bessant J., Pavitt K., Managing Innovation. Integrating Technological, Market and Organizational Change, John Wiley \& Sons, Chichester, 2005.

[17] Oprzędkiewicz J., Optimization methodology of construction with discrete parameter dependencies on 
their geometric features [in Polish: Metodyka optymalizacji konstrukcji o dyskretnych zależnościach parametrów od ich cech geometrycznych], Zeszyty Naukowe IOS, no 37, 1970.

[18] Oprzędkiewicz J., Computer assistance in the reliability of machines [in Polish: Wspomaganie komputerowe $w$ niezawodności maszyn], CAD/CAM, WNT, Warszawa 1993.

[19] Saranga H., Kumar U.D., Optimization of aircraft maintenance/support infrastructure using genetic algorithmslevel of repair analysis, Annals of Operations Research, Springer, pp. 91-106, March 2006.

[20] Gawlik J., Rewilak J., Tokaj T., New Efficiency Indicators of Innovative Products Implementation Process Realized on the Basis of Automotive Requirements [in Polish: Nowe wskaźniki efektywności procesu wdrażania nowatorskich wyrobów, realizowanego na podstawie wytycznych branży motoryzacyjnej], Zarządzanie Przedsiębiorstwem, 1, 210, 2013.
[21] Kokoszka S., Tabor S., Technological progress versus the structure of work time and outlay effectiveness in grain transport [in Polish: Postęp technologiczny a struktura czasu pracy $i$ efektywność naktadów $w$ transporcie ziarna], Problemy Inżynierii Rolniczej, 4, 30, 91-98, 2000.

[22] Butter F.A.G. den, Wollmer F.J., An empirical model for endogenous technology in the Netherlands, Economic Modeling, 13, 15-40, 1996.

[23] Berman S.J., Hagan J., How technology-driven business strategy can spur innovation and growth, Strategy \& Leadership, 34, 2, 2834, 2006.

[24] Hosmailin G., Investissement, rantabilite'et progre's Technique, pp. 119-120, Paris 1957.

[25] Muzalewski A., Operating costs of machines [in Polish: Koszty eksploatacji maszyn], Wyd. IBMER, pp. 1-39, Warszawa 2003.

[26] Skrypnyk A., The life safety and risk management optimization problem, Management and Production Engineering Review, 4, 2, 89-92, 2013. 